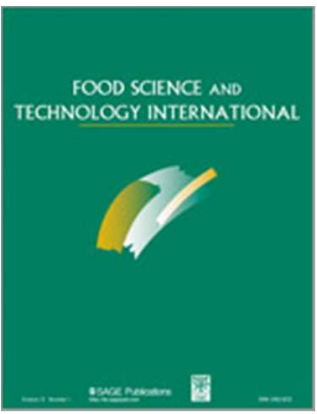

\title{
Lipid dynamics in blended wheat and non-wheat flours breadmaking matrices: impact on fresh and aged composite breads.
}

\begin{tabular}{|c|c|}
\hline Journal: & Food Science and Technology International \\
\hline Manuscript ID & FSTI-16-0288.R1 \\
\hline Manuscript Type: & Research Article \\
\hline Subject category: & Physical, Chemical and Sensory Properties \\
\hline Date Submitted by the Author: & $\mathrm{n} / \mathrm{a}$ \\
\hline Complete List of Authors: & $\begin{array}{l}\text { Collar, Concha; CSIC, Instituto de Agroquimica y Tecnologia de Alimentos } \\
\text { Conte, Paola }\end{array}$ \\
\hline Keywords: & Breadmaking, Quality assessment, Lipids \\
\hline Abstract: & $\begin{array}{l}\text { The use of pseudocereals, legumes and ancient grains for breadmaking } \\
\text { applications is receiving particular attention since they involve nutrient } \\
\text { dense grains with proven health-promoting attributes. Dilution up to } 45 \% \\
\text { of the basic wheat flour matrix by accumulative ternary addition of teff, } \\
\text { green pea and buckwheat flours did significantly impact both the } \\
\text { extractability and distribution of lipid subfractions in composite flours, } \\
\text { doughs and breads, and induced differentiated dynamics in lipid binding } \\
\text { along breadmaking. During mixing, a preferential covalent lipid binding to } \\
\text { the inside part of the starch granules takes place at the expenses of both } \\
\text { accessible free lipids and lipids initially bound non-covalently to the } \\
\text { gluten/non gluten proteins and to the outside part of the starch granules. } \\
\text { During fermentation and later baking a preferential lipid binding to the } \\
\text { gluten/non gluten proteins and to the outside and inside starch granules } \\
\text { takes place at the expenses of both a free lipid displacement and a bound } \\
\text { lipid translocation to new protein and starch active sites. It can be noticed } \\
\text { that the larger the accumulation of both protein- and starch-bound lipids } \\
\text { over fermentation and baking, the higher physic-chemical and sensory } \\
\text { profiles, and the slower starch hydrolysis, firming and retrogradation } \\
\text { kinetics of composite breads were obtained. }\end{array}$ \\
\hline
\end{tabular}




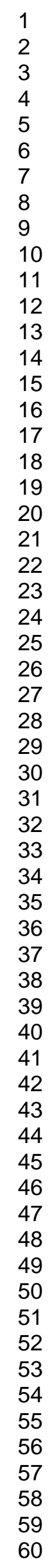

SCHOLARONE $^{\text {m }}$

Manuscripts

http://mc.manuscriptcentral.com/fsti 
1 Lipid dynamics in blended wheat and non-wheat flours breadmaking matrices: impact on fresh and

2 aged composite breads.

3

4 Concha Collar ${ }^{1 *}$, Paola Conte ${ }^{2}$

5

$6 \quad{ }^{1}$ Cereals and Cereal-based Products, Food Science Department, Instituto de Agroquímica y Tecnología de

7 Alimentos (CSIC). Avda. Catedrático Agustín Escardino, 7. 46980 Paterna. SPAIN.

$8 \quad$ 2Dipartimento di Agraria. Sezione di Scienze e Tecnologie Ambientali e Alimentari. Università degli Studi di

9 Sassari. Viale Italia, 39. 07100 Sassari. ITALY

10

11

$12{ }^{*}$ Corresponding author. Tel.: +34 9639000 22; Fax: +34 963636301

13 E-mail address: ccollar@iata.csic.es

14

15

16

17

18

19

20

21

22

23

http://mc.manuscriptcentral.com/fsti 
24 Abstract The use of pseudocereals, legumes and ancient grains for breadmaking applications is receiving 25 particular attention since they involve nutrient dense grains with proven health-promoting attributes. Dilution 26 up to $45 \%$ of the basic wheat flour matrix by accumulative ternary addition of teff, green pea and buckwheat

27 flours did significantly impact both the extractability and distribution of lipid subfractions in composite flours, 28 doughs and breads, and induced differentiated dynamics in lipid binding along breadmaking. During mixing,

29 a preferential covalent lipid binding to the inside part of the starch granules takes place at the expenses of 30 both accessible free lipids and lipids initially bound non-covalently to the gluten/non gluten proteins and to 31 the outside part of the starch granules. During fermentation and later baking a preferential lipid binding to 32 the gluten/non gluten proteins and to the outside and inside starch granules takes place at the expenses of 33 both a free lipid displacement and a bound lipid translocation to new protein and starch active sites. It can 34 be noticed that the larger the accumulation of both protein- and starch-bound lipids over fermentation and 35 baking, the higher physic-chemical and sensory profiles, and the slower starch hydrolysis, firming and 36 retrogradation kinetics of composite breads were obtained.

47 Keywords. Composite Bread . Nutritional quality · Functional properties . Lipid dynamics 


\section{Introduction}

Lipids provide a wide array of beneficial properties during breadmaking stages and bread storage

51 which reflects the overall lipid diversity. Over the past years, the role of lipids in the areas of gas cell

52 stabilisation (Sroan and MacRitchie, 2009) and the emulsifying properties of specific polar lipids (Selmair

53 and Koehler, 2010) has been particularly emphasized. Lipids have a significant effect on the quality and

54 texture of baked goods because of their ability to associate with proteins, due to their amphipathic nature

55 (hydrophilic and hydrophobic groups present), and with starch, forming inclusion complexes (Goesaert et

56 al., 2005). Nonpolar lipids are either associated with the glutenin polymeric network through hydrophobic

57 interactions or entrapped within the gluten matrix. In gluten, glycolipids are likely to be associated with

58 glutenins through both hydrophobic interactions and hydrogen bonds whilst phospholipids preferentially

59 interact with gliadins and lipid binding proteins (McCann et al., 2009). Amylose-lipid complexation can

60 prevent the cocrystallization of amylose with amylopectin, and lipids can also complex with the outer

61 branches of amylopectin and inhibit retrogradation in a more direct way (Putseys et al., 2010).

62 In breadmaking applications, protein and starch lipid binding in both wheat flour and additive-bread

63 systems have been reported to correlate with loaf volume, crumb structure, softness and/or texture of bread

64 (Collar et al., 2001; Angioloni \& Collar, 2011a). At dough level and in presence of surfactants, free and

65 bound lipids preferentially bind to gluten (monoglycerides) and to the outside part of the starch granules

66 (cationic surfactants). Hydrocolloids preferentially bind to the gluten and to the outside part of the starch

67 granules depending on their polarity (Collar et al., 1998). In wheat bread, a preferential binding of the added

68 anionic surfactant to the starch with a concomitant displacement of endogenous polar lipids from starch to

69 gluten was observed (Collar et al., 2001).

70 The binding of free lipids with gluten proteins may provide lipids with the ability to align at the interface

71 of gas cells during the initial phases of dough mixing and increase gas cell stability throughout the bread 
72 making process (Pareyt et al., 2011). Gas cells are retained in dough during fermentation and baking. Both

73 gluten and lipids play a role in this. Initially, during fermentation, the growing gas cells are surrounded

74 (Selmair \& Koehler, 2010) and stabilised by a continuous gluten network, the viscosity of the dough liquor

75 and the adsorbed lipid crystals. The gluten matrix remains only as a thin film between gas cells at the end of

76 fermentation and some surface active proteins and lipids exert film stabilising properties and, as such,

77 increase gas cell retention (Gan et al., 1995). The endogenous lipids and gluten proteins act synergistically

78 to stabilise the gas cells during fermentation.

79 In diluted wheat flour systems by addition of non-gluten forming grain flours, lipid binding during 80 breadmaking stages takes place to both gluten and non-gluten proteins and to mixed starches. In single and 81 blended oat, rye, buckwheat and wheat flour matrices, lipids bound to proteins during dough mixing are 82 translocated and bound to starch during baking. Lipids bound to starch showed the most significant 83 correlations with parameters related to dough and bread performance during breadmaking, especially over 84 the mixing step (Angioloni \& Collar, 2011a). In complex grain flour matrices, during baking, lipids bind to the

85 gluten/non gluten proteins at the expenses of both a free lipid displacement and a lipid migration from the 86 inside part of the starch granules to the protein active sites. It was observed that the higher the decrease of 87 free lipid content during baking, the higher the pasting temperature and the lower the total setback on 88 cooling and the dynamic moduli, but the higher the specific volume in blended breads (Collar and Angioloni, 89 2014).

90 Pseudocereals and teff flours exhibit richer qualitative and quantitative lipid profiles than green pea and 91 wheat flours (Hager et al., 2012). This research is aimed at characterising the lipid fractions of flour, dough 92 and bread stages in single and blended teff, green pea and buckwheat added to a wheat flour matrix. An 93 analysis of the impact of free lipids and starch- and protein-lipid binding along the breadmaking steps on the 94 physico-chemical and sensory properties and starch digestibility of composite matrices was presented.

95 
96 2. Experimental

97 2.1. Materials

98 Commercial flours from refined common wheat Triticum aestivum (W), and whole teff Eragrostis tef (T), 99 green pea Pisum sativum (GP), and buckwheat Fagopyrum esculentum (BW) were purchased from the 100 Spanish market. Protein, dietary fibre and fat contents (\% flour, dry basis) were 14.13\%, 2.19\%, 1.56 (W); $10125.12 \%, 14.56 \%, 1.27$ (GP); 19.71\%, 13.52\%, 3.44\% (BW), and 13.05\%, 12.19\%,5.06\% (T), respectively 102 (Collar et al., 2014a). Refined W flour (70\% extraction rate) of $356 \times 10^{-4} \mathrm{~J}$ energy of deformation W, 0.64 103 curve configuration ratio P/L, 95\% Gluten Index, 62\% water absorption in Brabender Farinograph, was 104 used. Ireks Vollsauer sour dough was from Ireks (Spain); Novamyl 10000 a maltogenic thermostable a105 amylase of 10,000 Maltogenase Units (MANU) of activity, from Novozymes (Denmark); and calcium 106 propionate, from Sigma-Aldrich (USA).

107

$108 \quad$ 2.2. Methods

109 Bread making of wheat and wheat-based blended flours

110 Doughs and breads were prepared from $\mathrm{W}$ as control, and wheat-based blended flours (T, GP, 111 BW) by W flour replacement from $22.5 \%$ up to $45 \%$, and incorporation of ternary blends of T, GP and BW 112 flours according to a Multilevel Factorial Design (Statgraphics Centurion XV, version 15.2.11, Statpoint 113 Technologies, Inc. Warrenton, Virginia, USA) with the following attributes: 3 experimental factors (T, GP and 114 BW flours) at 2 levels, coded 0 (7.5\% W flour replacement) and 1 (15\% W flour replacement), and 5 error 115 degrees of freedom. The model resulted in 8 randomized runs in 1 block. A 3 digit bread sample code was 116 set referring to low (0) ang high (1) W flour replacement by T (1st digit), GP (2 ${ }^{\text {nd }}$ digit), and BW (3rd digit) 117 flours in sample formulation, as it follows: $010,001,011,000,111,101,100,110$. Blended flours, water, 118 commercial compressed yeast, salt, sugar, commercial sour dough, milk powder, Novamyl 10000, and 119 calcium propionate were mixed, and used to make control and blended breads according to the quantitative 
120 formulations and breadmaking procedure described earlier (Collar et al., 2014a). Bread samples were

121 stored for $1,3,6$, and 8 days to describe firming kinetics. Two trials of baking tests per sample were 122 performed.

123

124 Sensory analysis

125 Sensory analysis of fresh breads was performed with a panel of ten trained judges (five males and

126 five females aged 24-57) using semi structured scales, scored 1-10 in which extremes (lowest:1; highest:

127 10) were described for each sensory attribute according to Setser (1996). Evaluated attributes were 128 grouped into visual (cell uniformity, size, brightness and shape, and cell wall thickness), textural (tactile 129 moistness, elasticity and smoothness, and biting coarseness, adhesiveness, cohesiveness, chewiness, 130 crumbliness and dryness) and organoleptic (taste intensity, quality, saltiness, sourness and aftertaste, and 131 aroma intensity, quality and sourness) characteristics. (Collar et al., 2005).

133 Starch digestibility

134 In vitro starch hydrolysis kinetics and relevant starch fractions in freeze-dried and ground fresh 135 blended breads was determined following the AACC (2005) method 32-40, adapted by Angioloni \& Collar 136 (2011b) as previously described (Collar et al., 2014a). Rapidly Digestible Starch (RDS) and Slowly 137 Digestible Starch (SDS) were measured after incubation for $20 \mathrm{~min}$ and $120 \mathrm{~min}$, respectively. Digestible 138 starch (DS) was calculated by the sum of RDS and SDS. Total starch (TS) was calculated by the sum of DS 139 and RS. A first order kinetic equation $\left[C=C_{\infty}\left(1-e^{-k t}\right)\right]$ was applied to describe the kinetics of starch 140 hydrolysis, where $C, C_{\infty}$ and $k$ were the hydrolysis degree at each time, the maximum hydrolysis extent and 141 the kinetic constant, respectively. Resistant starch (RS) determination was performed according to AOAC 142 Official Method 2002.02 (AOAC, 2000) and AACC Method 32-40 (AA CC, 2005), as described by 
143 Megazyme International Ireland (2011) in the Resistant Starch Assay Procedure (kit K-RSTAR 08/11).

144 Three replicates were made per analysis.

145

146 Textural measurements and firming kinetics

147 Bread mechanical characteristics (TPA in a double compression cycle) of fresh and stored breads 148 were recorded in a TA-XTplus texture analyser (Stable Micro Systems, Surrey, UK) using a 25 mm diameter

149 cylindrical aluminium probe, a $5 \mathrm{~kg}$ load cell, $50 \%$ penetration depth at a running speed of $1 \mathrm{~mm} / \mathrm{s}$, and a 30

150 s gap between compressions on crust-free slices of $25 \mathrm{~mm}$ width (Armero \& Collar, 1998). For textural

151 measurements, three slices of two breads were used for each sample. The obtained firming curves during

152 bread storage were modelled using the Avrami equation, and model factors were estimated by fitting

153 experimental data of hardness to the nonlinear regression equation $\theta=\frac{T_{\infty}-T_{t}}{T_{\infty}-T_{0}}=e^{-k t^{n}}$ where $\theta$ is the

154 fraction of the recrystallisation still to occur; $T_{0}, T_{\infty}$ and $T_{\mathrm{t}}$ are crumb firmness at time zero, $\infty$ and time t,

155 respectively, $k$ is a rate constant, and $n$ is the Avrami exponent.

157 Thermal measurements and retrogradation kinetics

$158 \quad$ Thermal properties regarding starch retrogradation of control and blended samples were assessed 159 in a Differential Scanning Calorimeter Perkin-Elmer DSC-7 (Norwalk, USA) as previously reported by Collar 160 et al. (2015). Stored previously gelatinized dough samples (Collar et al., 2015) were submitted to a second 161 DSC scan to analyze starch retrogradation at the different storage periods after $1,3,6$, and 8 days. 162 Scanning conditions included keeping sample pans at $25^{\circ} \mathrm{C}$ for $1 \mathrm{~min}$, and then heating from 25 to $130^{\circ} \mathrm{C}$ at 163 a rate of $10^{\circ} \mathrm{C} / \mathrm{min}$. The enthalpy of amylopectin retrogradation $\left(\Delta H_{r}\right)$ was calculated, and $T_{0}, T_{p}$, and $T_{e}$ for 164 the thermal transitions, identified. All samples were analyzed in duplicate. Modelling of crystallization data 165 was carried out using the Avrami equation, and model factors were estimated by fitting experimental data 
166 for melting enthalpies to the nonlinear regression equation $\theta=\frac{H_{\infty}-H_{t}}{H_{\infty}-H_{0}}=e^{-k t^{n}}$ where $\Theta$ is crystallinity, $167 H_{\infty}$, is the levelling-off value of melting enthalpy at which the extent of crystallization in starch stoped, $H_{t}$ is 168 the melting enthalpy at time $t$, and $H_{0}$ is the melting enthalpy at initial time, $t$ is time of crystallization, $k$ is a 169 rate constant, and $n$ is the Avrami exponent.

$171 \quad$ Lipid determinations

172 Flour, dough and bread free lipids (FL).--Flour (10g), ground freeze-dried dough $(10 \mathrm{~g})$ and ground freeze173 dried bread $(20 \mathrm{~g})$ samples were extracted with light petroleum ether under reflux conditions for 90 min in a 174 soxhlet (McCormack et al., 1991) The solvent was removed under vacuum and the extracts were 175 determined gravimetrically. Determinations were made per duplicate.

176 Flour and dough bound lipids (BL).- Residues of the FL extraction were extracted with chloroform under 177 reflux conditions as described by McCormack et al. (1991) to obtain total bound lipids (non-covalent forces)

178 to both starch and proteins (BL). Determinations were made per duplicate.

179 Bread protein-bound lipids (PBL).- Residues of FL extraction (10g) were treated with 100mL 1\% pepsin in $18050 \mathrm{mM}$ sulphuric acid, ( $\mathrm{pH} \mathrm{1.6)}$ and gently stirred for $4 \mathrm{~h}$ at $40^{\circ} \mathrm{C}$ under the conditions described by Collar et 181 al. (2001). This fraction specifically refers to lipids easily or strongly bound to proteins. Determinations were 182 made per duplicate.

183 Starchy lipids (SL).- Flour and dough starchy lipids were obtained by acid hydrolysis of the non-starchy lipid184 free residue (ICC 136). This fraction specifically refers to lipids covalently bound to starch. Determinations 185 were made per duplicate.

186 Bread starch-bound lipids (SBL).- Residues of FL extraction (10g) were reacted with $100 \mathrm{~mL} \quad 0.5 \%$ a187 amylase in $10 \mathrm{mM} \mathrm{NaH} 2 \mathrm{PO} 4,(\mathrm{pH} 6.5)$ and gently stirred for $4 \mathrm{~h}$ at $70^{\circ} \mathrm{C}$. When the reaction was completed, $188100 \mathrm{~mL}$ of $\mathrm{Cl} 3 \mathrm{CH}$ were added, and the mixture stirred for $1 \mathrm{~h}$ at room temperature and centrifuged. 
189 Supernatants were washed with $5 \% \mathrm{NaCl}$, the solvent removed, weighed (SBL) and stored under nitrogen

190 until analysis (Collar et al., 2001). This fraction specifically refers to lipids easily or strongly bound to starch

191 granules either by non-covalent (outside) or covalent forces (inside). Determinations were made per

192 duplicate.

193 Total lipids were indirectly determined by addition of $F L+B L+S L$ amounts retrieved in flours and doughs,

194 and by addition of $F L+P B L+S B L$ levels determined in breads. All lipid fractions and subfractions

195 determinations were made per duplicate, and contents were expressed in $\mathrm{g} / 100 \mathrm{~g}$ flour basis, as is.

197 Statistical analysis

198 Multivariate analysis of variance and correlation matrix of data were performed by using Statgraphics

199 V.7.1 program (Bitstream, Cambridge, MN). Multiple range test (Fisher's least significant differences, LSD)

200 for analytical variables was applied to know the difference between each pair of means.

201

202 3. Results and discussion

203

204 Plural physic-chemical and biochemical approaches have been performed (a) to know the qualitative and 205 quantitative profiles of endogenous lipid fractions of single and multigrain flour, dough and bread matrices 206 and (b) to link lipid binding along breadmaking to the sensory, physical, starch hydrolysis, firming and starch 207 retrogradation kinetics parameters in fresh and aged composite bread matrices.

208

209 3.1. Lipid extractability and distribution in single and multigrain flour, dough and bread samples

210 Data for extractability ( $\mathrm{g} / 100 \mathrm{~g}$ flour) and distribution (\% of total lipids) of lipid fractions and sub-fractions

211 from single and blended flour, dough and bread samples are reported in Table 1 and Figure 1, respectively.

212 Total lipids ( $\mathrm{g} / 100 \mathrm{~g}$ flour basis) in single flours ranged from $1.85 \mathrm{~g}(\mathrm{~W})$ to $4.91 \mathrm{~g}(\mathrm{~T})$, in mixed flours from 
$2131.85 \mathrm{~g}(\mathrm{~W})$ to $2.57 \mathrm{~g}$ (111), in doughs from $1.20 \mathrm{~g}$ (W) to $2.47 \mathrm{~g}$ (101), and in breads from $1.44 \mathrm{~g}$ (W) to 3.12

$214 \mathrm{~g}(101)$ (Table 1). The total lipid content determined in this study is in general in line with results previously

215 found by Collar et al. $(1998,2001)$ for wheat, Schloenlechner et al., (2008) for pseudocereals, de Almeida

216 Costa et al., (2006) for green pea, and Hager et al. (2012) for pseudocereals and teff flours.

217 Free lipid (FL) was the most prominent fraction in terms of absolute content (Table 1) and as a percentage

218 of total lipids (Figure 1) in flour (except for GP) and dough samples (except for control W); whereas in

219 general, protein-bound lipids (PBL) and starch-bound lipids (SBL) predominated in breads with some

220 exceptions. Bound lipids (BL) were minor lipid fraction in all single and blended flour matrices, while starchy

221 lipids (SL) accounted for intermediate quantitative lipid fractions in blended flours and doughs (Table 1). FL

222 in single grain flours varied greatly (from $0.58-G P-$ to $4.14-T-, \mathrm{g} / 100 \mathrm{~g}$ flour basis, accounting from 28

223 to $84 \%$ of total lipids, respectively), little in blended flours (from $1.33-010-$ to $1.70-101-, \mathrm{g} / 100 \mathrm{~g}$ flour

224 basis), doughs (from $0.75-010$ - to $1.45-101-, \mathrm{g} / 100 \mathrm{~g}$ flour basis, accounting from 44 to $59 \%$ of total

225 lipids) and breads (from 0.42-010-to 0.93-001, 100-, g/100 $\mathrm{g}$ flour basis, accounting from 18 to 31-

$22643 \%$ of total lipids). PBL in breads varied from 26 (111) to $47 \%$ (010) of total lipids, while SBL accounted

227 from 25 (001) to $53 \%$ (111) of total lipids (Figure 1).

228 Increased addition of any non-wheat grain flour from 7.5 (0) to $15 \%$ (1) significantly changed the quali and 229 quantitative lipid profile of blended flours, doughs and breads, especially for T and GP (Table 2). At flour

230 level, blending W flour with increasing amounts of either T or BW promoted the amount of FL by $13-19 \%$

231 with a concomitant increase of TL by $9-11 \%$, while higher levels of GP induced a decline in FL by $9 \%$ and a

232 promotion of both BL (12\%) and SL (5\%) in blended flours, encompassing poorer extractability (-4\%) of TL

233 (Table 2). At dough level, a significant $(p<0.01)$ increase of $\mathrm{FL}(+40 \%)$ and $\mathrm{BL}(+28 \%)$ was provided by

234 blending higher levels of T and GP flours, respectively, which derived in depletion of respective BL (-11\%)

235 and FL $(-16 \%)$ in composite doughs thereof. At bread stage, GP incorporation at higher levels favoured

236 accumulation of SBL (+17\%) at the expenses of a notable depletion of FL $(-40 \%)$; whereas blending higher 
237 levels of either T or BW resulted in a common decrease in PBL (-13 to $-27 \%)$ and an accumulation (+29\%, $238 \mathrm{~T})$ or depletion $(-23 \%, \mathrm{BW})$ in SBL (Table 2). The overall result in TL balance was a net increase by $10 \%$ in

239 high-T formulated breads, and a net decrease by - $9 \%$ (GP) and -14 \% (BW), respectively. Simultaneous 240 presence of non-wheat flours at different levels of wheat replacement induced significant interactions on 241 major free and bound lipid subfractions of breadmaking matrices, particularly for T/GP and T/BW (Table 2).

242 Higher levels of T (1) in presence of lower amounts of GP (0) provided maximum extractability (g/100g flour) 243 for FL in blended flours $(1.79 \mathrm{~g})$, and doughs $(1.37 \mathrm{~g})$, TL in mixed flours $(2.64 \mathrm{~g})$ and breads $(2.76 \mathrm{~g})$, and 244 PBL $(0.87 \mathrm{~g})$ in breads (Table 2). Whereas, in presence of lower amounts of BW (0), higher T (1) 245 replacement maximized SBL $(1.29 \mathrm{~g})$ and $\mathrm{TL}(2.83 \mathrm{~g})$ in composite breads. Last results were of the order of 246 those found for the pair GP/BW at 0/0 levels (Table 2).

$248 \quad 3.2$. Lipid binding during mixing, fermentation and baking of composite matrices

249 Along breadmaking steps -mixing, fermentation and baking-, lipid subfractions of composite matrices 250 underwent significant quantitative changes as a result of a balance between a) release of protein- and/or 251 starch-bound lipids to the pool of free lipids, b) binding of free lipids to protein and/or starch and c) 252 translocation of protein-bound lipids to starch-bound lipids and/or vice versa.

253 During mixing, a variable depletion of the pool of FL -from $-11 \%(110)$ to $-44 \%(010,011)$ - was denoted in 254 composite matrices, in accordance with a discreet variation in $\mathrm{BL}-$ from $-17 \%(100)$ to $+9 \%(011)$ - and a 255 moderate promotion of SL -from $+8 \%$ (100) to $+35 \%$ (101)- (Figure 2). Increased amounts of either GP or 256 BW from level 0 to level 1 promoted the extent of the changes in FL and minimized those in $B L$, while 257 increased T replacement led to opposite effects. Control samples on W observed a different lipid pattern 258 during mixing: maximum depletion in $\mathrm{FL} \mathrm{(-79 \% )} \mathrm{and} \mathrm{notable} \mathrm{accumulation} \mathrm{of} \mathrm{both} \mathrm{BL}(+21 \%)$ and $\mathrm{SL}$ $259(+27 \%)$. After consecutive fermentation and baking steps of composite matrices, FL decreased from $-37 \%$ 260 (001) to $-72 \%$ (111), while a variable sharp increase was denoted for both $\mathrm{PBL}$-from $60 \%$ (111) to $236 \%$ 
261 (101)- and SBL -from 53\% (010) to 175\% (101)- (Figure 2). Increasing amounts of any non-wheat flour 262 moderated the changes in PBL but enhanced those of SBL. In absence of non-wheat flours, lipid dynamics 263 of W systems followed a notable decrease in FL $(-59 \%)$, a moderate increase of PBL $(+53 \%)$, and a 264 discreet accumulation of SBL (+13\%) (Figure 2).

265

266

267

\subsection{Relationships between lipid dynamics along breadmaking of composite matrices and physico-} chemical, sensory and nutritional properties of fresh and aged breads.

268 Mixing of composite matrices induced binding from flour to dough of both $\mathrm{FL}$ and $\mathrm{BL}$ through a respective 269 sharp decrease up to $-44 \%$ in the pool of free lipids and a slight decrease in BL up to $-17 \%$. Concomitantly, 270 a prominent accumulation of SL up to $17 \%$ took place in blended doughs (Figure 2). So that, a preferential 271 covalent lipid binding to the inside part of the starch granules takes place during mixing at the expenses of 272 both accessible free lipids and lipids initially bound non-covalently to the gluten/non gluten proteins and to 273 the outside part of the starch granules. Results are in contrast with those found for W systems, where 274 around $80 \%$ of FL migrated to the active sites of both gluten and starch leading to a notable accumulation of $275 \mathrm{BL}$ and SL in doughs, respectively (Figure 2). In wheat systems, it has been reported than more than half of 276 the free lipids in flour become associated with the gluten protein during dough mixing (Chung, 1986). The 277 association could involve either physical entrapment or binding of lipids to protein (Carr et al., 1992), and as 278 a result, some of the flour lipids can no longer be extracted with the non-polar solvents used for free lipid 279 extraction. The protein and lipid might be associated through a) chemical interactions involving polar and 280 hydrophobic bonding (Pomeranz and Chung, 1978), suggesting that dough is strengthened by the ability of 281 polar lipids to be associated with protein and starch and/or b) lipid is retained within the gluten in a relatively 282 non-specific way and that the interaction of protein and lipid in gluten may involve the physical entrapment 283 of lipid and also polar or ionic bonding between the components (Carr et al., 1992). 284 It has been alluded that the binding of free lipids with gluten proteins may provide them with the ability to 
285 align at the interface of gas cells during the initial phases of dough mixing and increase gas cell stability 286 throughout the bread making process (Pareyt et al., 2011). When non-gluten forming flours are added to the 287 breadmaking system, interpherences in the binding of lipids to main biopolymers -protein, starch- can occur 288 since original wheat flour system is diluted with other fat, protein, starch and dietary fibre entities that 289 compete for water and active sites of biomolecules. This is the case of the present flours used, whose 290 chemical composition is particularly rich in fat (T, BW), protein (GP, BW) and dietary fibre (T, GP, BW).

291 Transformation of dough into bread after successive fermentation and baking steps induced binding of FL 292 and most probably also of $\mathrm{BL}$ from dough to bread through a sharp decrease in the pool of $\mathrm{FL}$ and a 293 concomitant increase in PBL and SBL of mixed breads (Figure 2). This means that a preferential lipid 294 binding to the gluten/non gluten proteins and to the outside and inside starch granules takes place during 295 fermentation and later baking at the expenses of both a FL displacement and a BL translocation to new 296 protein and starch active sites. Nature of pseudocereal proteins -highly soluble and foaming and 297 emulsifying properties- (Schloenchner et al., 2008), and teff prolamins -lower polymerization, hydrophobicity 298 and denaturation temperature- (Adebowale et al., 2011), can stimulate lipid binding, particularly for the most 299 accessible fraction (FL). In fact, in control W systems, FL migration takes places mainly to the gluten protein 300 active sites and very little to the starch leading to a discreet accumulation of PBL and a poor increase of 301 SBL from dough to bread (Figure 2).

302 Dynamics on FL and BL during mixing significantly $(p<0.01)$ correlated (coefficient of correlation, $r$ ) with 303 some sensory, physical and nutritional features in fresh blended breads: the higher the decrease of FL 304 content over mixing, the higher the cell uniformity $(r=-0.553)$, the moistness $(r=-0.761)$ and the elasticity $(r=-$ $3050.616)$ of bread crumb, and the higher the SDS $(r=-0.523)$ and RS $(r=-0.530)$ formation upon starch 306 hydrolysis; the higher the displacement of BL over mixing, the softer ( $r=-0.460)$, the more cohesive ( $r=-$ 307 0.593) and springier ( $r=-0.381)$ the bread crumb became in blended breads (Table 3). 
308 Dynamics on PBL and SBL during fermentation and baking significantly $(p<0.01)$ correlated with main

309 sensory features and physical characteristics in fresh breads, and with firming and retrogradation kinetics

310 on ageing. It can be noticed that the higher the accumulation of PBL over fermentation and baking, the

311 larger the bread volume $(r=0.453)$, and the softer $(r=0.640)$ and the more cohesive $(r=0.625)$ bread crumbs

312 are obtained, undergoing slower starch hydrolysis $(r=-0.530)$ and retrogradation kinetics $(r=-0.674)$ in

313 blended breads (Table 3). Increased accumulation of SBL after fermentation and baking significantly

314 impacted the sensory perception of subsequent mixed breads mainly in terms of decreased cell uniformity

$315(r=-0.900)$, brighter $(r=0.810)$, less elastic $(r=-0.768)$, but more cohesive $(r=0.755)$ fresh bread crumb, with

316 slower both firming ( $r=-0.835)$ and starch retrogradation ( $r=-0.561)$ kinetics (Table 3).

318 4. Conclusions

319 Dilution up to $45 \%$ of the basic wheat flour matrix by accumulative ternary addition of teff, green pea and 320 buckwheat flours $(7.5 \%-15 \%$ single flour $)$ did significantly $(p<0.01)$ impact both the extractability and

321 distribution of lipid subfractions in composite flours, doughs and breads, and induced dynamics in lipid 322 binding over mixing, fermentation and baking steps, in variable extent. At dough level, a significant 323 promotion of FL or BL was provided by blending higher levels of $T$ or GP flours, respectively, which 324 encompassed a depletion of respective BL or FL in composite doughs thereof. At bread stage, GP 325 incorporation at higher levels favoured accumulation of $\mathrm{SBL}$ at the expenses of a notable depletion of $\mathrm{FL}$, 326 whereas blending larger amounts of either T or BW resulted in a common decrease in PBL and an 327 accumulation (T) or depletion (BW) in SBL.

328 During mixing, a preferential covalent lipid binding to the inside part of the starch granules takes place at the 329 expenses of both accessible free lipids and lipids initially bound non-covalently to the gluten/non gluten 330 proteins and to the outside part of the starch granules in flours. Results are in contrast with those found for 331 W systems, where around $80 \%$ of FL migrated to the active sites of both gluten and starch leading to a 
332 notable accumulation of $B L$ and $S L$ in doughs, respectively. Higher depletion in FL contents over mixing

333 corresponded to more uniform cell structure, moist and elastic bread crumbs, exhibiting larger formation of

334 both SDS and RS upon starch hydrolysis. Concomitantly, the higher the displacement of BL over mixing,

335 the softer, the more cohesive and springier the bread crumb was in blended breads.

336 During fermentation and later baking a preferential lipid binding to the gluten/non gluten proteins and to the

337 outside and inside starch granules takes place at the expenses of both a FL displacement and a BL

338 translocation to new protein and starch active sites. It can be noticed that the higher the accumulation of

339 PBL over fermentation and baking, the larger the bread volume, and the softer and the more cohesive

340 bread crumbs are obtained, undergoing slower starch hydrolysis and retrogradation kinetics in composite

341 breads. Increased accumulation of SBL after fermentation and baking significantly impacted the sensory

342 perception of subsequent mixed breads mainly in terms of decreased cell uniformity, brighter, less elastic,

343 but more cohesive fresh bread crumbs, with slower both firming and starch retrogradation kinetics.

345 5. Acknowledgements

346 The authors acknowledge the financial support of Consejo Superior de Investigaciones Cientificas (CSIC),

347 Ministerio de Economía y Competitividad (MINECO) and Fondo Europeo de Desarrollo Nacional (FEDER)

348 (Project AGL2015-63849-C2-1-R).

349

350 6. References

351 AACC 2005. Approved methods of the American Association of Cereal Chemists, AA CC. 10th edition, St. 352 Paul, Minn.

353 Adebowale A. A., Emmambux, M. N., Beukes, M., \& Taylor, J. R. N. (2011). Fractionation and 354 characterization of teff proteins. Journal of Cereal Science, 54, 380-386. 
355 Angioloni, A., \& Collar, C. (2011a). Significance of lipid binding on the functional and nutritional profiles of 356 single and multigrain matrices. European Food Research and Technology, 233,141-150.

357 Angioloni, A., \& Collar, C. (2011b). Physicochemical and nutritional properties of reduced-caloric density 358 high-fibre breads. LWT - Food Science and Technology, 44, 747-758.

359 AOAC. (2000). Official Methods of Analysis 17th Ed., AOAC International.

360 Armero, E., \& Collar, C. (1998). Crumb firming kinetics of wheat breads with antistaling additives. Journal of $361 \quad$ Cereal Science, 28, 165-174.

362 Carr, N. O., Daniels, N. W. R., \& Frazier, P. J. (1992). Lipids interactions in breadmaking. Critical Reviews 363 in Food Science and Nutrition, 31(3), 237-258.

364 Chung, O. K. (1986). Lipids-protein interactions in wheat flour, dough, gluten, and protein fractions. Cereal $365 \quad$ Foods World, 31(3), 242-256.

366 Collar, C., \& Angioloni, A. (2014). Pseudocereals and teff in complex breadmaking matrices: impact of lipid 367 dynamics on the bread functional and nutritional profiles. Journal of Cereal Science, 59, 145-154.

368 Collar, C., Bollaín, C., \& Angioloni, A. (2005). Significance of microbial transglutaminase on the sensory, 369 mechanical and crumb grain pattern of enzyme supplemented fresh pan breads. Journal of Food $370 \quad$ Engineering, 70, 479-488.

371 Collar, C., Jiménez, T., Conte, P., \& Fadda, C. (2014a). Impact of ancient cereals, pseudocereals and 372 legumes on starch hydrolysis and antiradical activity of technologically viable blended breads. $373 \quad$ Carbohydrate Polymers, 113, 149-158.

374 Collar, C., Jiménez, T., Conte, P., \& Piga, A. (2015). Significance of thermal transitions on starch 375 digestibility and firming kinetics of restricted water mixed flour bread matrices. Carbohydrate Polymers, $376 \quad 122,169-179$.

377 Collar, C., Armero, E., \& Martínez, J. (1998). Lipid binding of formula bread doughs Relationships with 378 dough and bread technological performance. Z. Lebensm Unters Forsch A, 207, 110-121. 
379 Collar, C., Martínez, J. C., \& Rosell, C. M. (2001). Lipid Binding of Fresh and Stored Formulated Wheat

380 Breads. Relationships with Dough and Bread Technological Performance. Food Science and 381 Technology International, 7/6, 501-510.

382 de Almeida Costa G.E., da Silva Queiroz-Monici K., Reis A.M.P.M., \& de Oliveira A.C. (2006). Chemical 383 composition, dietary fibre and resistant starch contents of raw and cooked pea, common bean, $384 \quad$ chickpea and lentil legumes. Food Chemistry, 94, 327-330.

385 Gan, Z., Ellis, P.R., \& Schofield, J.D. (1995). Gas cell stabilization and gas retention in wheat bread dough. $386 \quad$ Journal of Cereal Science 21, 215-230.

387 Goesaert, H., Brijs, K., Veraverbeke, W. S., Courtin, C. M., Gebruers, K., \& Delcour, J. A. (2005). Wheat 388 flour constituents: how they impact bread quality, and how to impact their functionality. Trends in Food 389 Science and Technology, 16, 12-30.

390 Hager, A. S., Wolter, A. Jacob, F., Zannini, E., \& Arendt, E. K. (2012). Nutritional properties and ultra391 structure of commercial gluten free flours from different botanical sources compared to wheat flours. 392 Journal of Cereal Science, 56, 239-247.

393 ICC, 1976-1996. ICC Standard Methods of the International Association for Cereal Chemistry. 104/1, 105/2, $394 \quad 110 / 1,115 / 1,136,162,166$. The Association: Vienna.

395 McCann,T. H., Small, D. M., Batey, I. L., Wrigley, C. W., \& Day, L. (2009). Protein-lipid interactions in 396 gluten elucidated using acetic-acid fractionation. Food Chemistry 115, 105-112.

397 McCormack G., Panozzo J., Bekes, F., \& MacRitchie F. (1991). Contributions to breadmaking of inherent 398 variations in lipid content and composition of wheat cultivars. I. Results of survey. Journal of Cereal 399 Science, 13, 255-261.

400 Pareyt, B., Finnie, S. M., Putseys, J. A., \& Delcour, J. A. (2011). Lipids in bread making: Sources, 401 interactions, and impact on bread quality. Journal of Cereal Science, 54, 266-279. 
402 Pomeranz, Y., \& Chung, O. K. (1978). Interaction of lipids with proteins and carbohydrate in breadmaking. 403 Journal of the American Oil Chemists' Society, 55, 285-289.

404 Putseys, J.A., Lamberts, L., \& Delcour, J.A. (2010). Amylose-inclusion complexes: Formation, identity and 405 physico-chemical properties. Journal of Cereal Science, 51, 238-247.

406 Schoenlechner, R., Siebenhandl, S., \& Berghofer, E. (2008). Pseudocereals. In: Arendt, E.K., Dal Bello, F. 407 Eds., Gluten-free Cereal Products and Beverages, Ireland, Cork, pp. 149-176.

408 Selmair, P.L., \& Koehler, P. (2010). Role of glycolipids in breadmaking. Lipid Technology 22, 7-10.

409 Setser, C.S. (1996). Sensory methods. In: Baked goods freshness, R.E. Hebeda, H.F. Zobel (Eds.), Marcel $410 \quad$ Decker Inc, New York (1996), pp. 171-187.

411 Sroan, B., \& MacRitchie, F. (2009). Mechanism of gas cell stabilization in breadmaking. II. The secondary 412 liquid lamellae. Journal of Cereal Science, 49, 41-46. 413 
Table 1 .- Lipid subfractions ( $\mathrm{g} / 100 \mathrm{~g}$ of flour) from single flours and blended doughs and breads (mean values of three replicates \pm standard deviation).

\begin{tabular}{|c|c|c|c|c|c|c|c|c|c|c|c|c|}
\hline \multirow[t]{2}{*}{ Code $^{1}$} & \multicolumn{3}{|l|}{ Free lipids } & \multicolumn{2}{|l|}{$\begin{array}{l}\text { Bound } \\
\text { lipids }\end{array}$} & \multirow{2}{*}{$\begin{array}{c}\begin{array}{c}\text { Protein- } \\
\text { bound }\end{array} \\
\text { Bread } \\
\end{array}$} & \multicolumn{2}{|l|}{$\begin{array}{l}\text { Starchy } \\
\text { lipids }\end{array}$} & \multirow{2}{*}{$\begin{array}{l}\text { Starch } \\
\text { bound } \\
\text { Bread } \\
\end{array}$} & \multicolumn{3}{|l|}{$\begin{array}{l}\text { Total } \\
\text { Lipids }\end{array}$} \\
\hline & Flour & Dough & Bread & Flour & Dough & & Flour & Dough & & Flour & Dough & Bread \\
\hline 010 & $1.33 \pm 0.09$ & $0.75 \pm 0.08$ & $0.42 \pm 0.08$ & $0.37 \pm 0.06$ & $0.35 \pm 0.09$ & $1.09 \pm 0.09$ & $0.54 \pm 0.08$ & $0.62 \pm 0.04$ & $0.82 \pm 0.12$ & 2.23 & $\begin{array}{l}1.72 \\
\end{array}$ & 2.33 \\
\hline 001 & $1.47 \pm 0.11$ & $1.13 \pm 0.09$ & $0.93 \pm 0.07$ & $0.33 \pm 0.05$ & $0.31 \pm 0.07$ & $0.70 \pm 0.09$ & $0.52 \pm 0.06$ & $0.60 \pm 0.09$ & $0.54 \pm 0.09$ & 2.33 & 2.04 & 2.17 \\
\hline 011 & $1.44 \pm 0.13$ & $0.82 \pm 0.10$ & $0.49 \pm 0.10$ & $0.37 \pm 0.07$ & $0.40 \pm 0.10$ & $0.80 \pm 0.12$ & $0.54 \pm 0.09$ & $0.61 \pm 0.06$ & $0.97 \pm 0.12$ & 2.34 & 1.84 & 2.26 \\
\hline 000 & $1.37 \pm 0.08$ & $1.08 \pm 0.12$ & $0.51 \pm 0.11$ & $0.32 \pm 0.08$ & $0.32 \pm 0.11$ & $1.02 \pm 0.10$ & $0.52 \pm 0.05$ & $0.67 \pm 0.12$ & $1.05 \pm 0.13$ & 2.21 & 2.07 & 2.58 \\
\hline 111 & $1.67 \pm 0.12$ & $1.33 \pm 0.09$ & $0.47 \pm 0.09$ & $0.37 \pm 0.02$ & $0.36 \pm 0.09$ & $0.59 \pm 0.11$ & $0.54 \pm 0.03$ & $0.66 \pm 0.09$ & $1.18 \pm 0.10$ & 2.57 & 2.36 & 2.24 \\
\hline 101 & $1.70 \pm 0.11$ & $1.45 \pm 0.08$ & $0.59 \pm 0.09$ & $0.33 \pm 0.05$ & $0.32 \pm 0.08$ & $1.10 \pm 0.11$ & $0.52 \pm 0.10$ & $0.70 \pm 0.10$ & $1.44 \pm 0.09$ & 2.55 & 2.47 & 3.12 \\
\hline 100 & $1.60 \pm 0.07$ & $1.21 \pm 0.13$ & $0.93 \pm 0.08$ & $0.32 \pm 0.10$ & $0.27 \pm 0.08$ & $0.86 \pm 0.08$ & $0.52 \pm 0.09$ & $0.56 \pm 0.11$ & $1.26 \pm 0.09$ & 2.44 & 2.04 & 3.06 \\
\hline 110 & $1.39 \pm 0.08$ & $1.24 \pm 0.12$ & $0.56 \pm 0.11$ & $0.37 \pm 0.09$ & $0.35 \pm 0.07$ & $0.79 \pm 0.07$ & $0.53 \pm 0.08$ & $0.65 \pm 0.09$ & $1.22 \pm 0.08$ & 2.29 & 2.24 & 2.57 \\
\hline Control & $1.06 \pm 0.10$ & $0.22 \pm 0.06$ & $0.43 \pm 0.09$ & $0.28 \pm 0.11$ & $0.34 \pm 0.12$ & $0.43 \pm 0.02$ & $0.51 \pm 0.10$ & $0.65 \pm 0.06$ & $0.57 \pm 0.11$ & 1.85 & 1.20 & 1.44 \\
\hline \multicolumn{13}{|l|}{ Flours $^{2}$} \\
\hline W & $1.06 \mathrm{~b}$ & & & $0.28 a$ & & & $0.51 a$ & & & 1.85 & & \\
\hline $\mathrm{T}$ & $4.14 d$ & & & $0.28 a$ & & & $0.48 a$ & & & 4.91 & & \\
\hline GP & $0.58 \mathrm{a}$ & & & $0.83 b$ & & & $0.68 b$ & & & 2.09 & & \\
\hline BW & $2.50 \mathrm{c}$ & & & $0.32 a$ & & & $0.54 a$ & & & 3.36 & & \\
\hline
\end{tabular}

${ }_{1}$ Blended samples were based on: wheat (W), teff (T), green pea (GP), and buckwheat (BW). Three digit sample code refers to low (0) ang high (1) wheat flour replacement by T: GP: BW flours in sample formulation.

2 Within each column of single flour samples, values with different letters differ significantly from each other $(p<0.05)$. 
Table 2.- Significant $\left(p<0.01,{ }^{* *}\right)$ single and $2^{\text {nd }}$ order interactive effects of non-wheat flours -teff $(T)$, green pea (GP), buckwheat (BW)on lipid subfractions contents -free lipids (FL), bound lipids (BL), starchy lipids (SL), protein bound lipids (PBL) and starch-bound lipids $(\mathrm{SBL})$ in composite matrices.

\begin{tabular}{|c|c|c|c|c|c|c|c|c|c|c|c|c|c|c|c|}
\hline \multirow{2}{*}{$\begin{array}{l}\text { Parameter, } \\
\text { (g/ } 100 \mathrm{~g} \text { flour) }\end{array}$} & \multicolumn{8}{|c|}{ Single effects ${ }^{1}$} & \multicolumn{7}{|c|}{ 2nd order Interactions ${ }^{1}$} \\
\hline & Level $^{2}$ & $\begin{array}{l}\text { Overall } \\
\text { mean }\end{array}$ & $T$ & ** & GP & ** & BW & ** & Level $^{2}$ & $T^{*} \mathrm{GP}$ & ** & $T * B W$ & ** & $G P$ * BW & ** \\
\hline FL Flour & $\begin{array}{l}0 \\
1\end{array}$ & 1.53 & $\begin{array}{l}1.40 \pm 0.03 \\
1.66 \pm 0.05\end{array}$ & $\begin{array}{l}a \\
b\end{array}$ & $\begin{array}{l}1.60 \pm 0.05 \\
1.46 \pm 0.03\end{array}$ & $\begin{array}{l}\mathrm{b} \\
\mathrm{a}\end{array}$ & $\begin{array}{l}1.44 \pm 0.03 \\
1.63 \pm 0.05\end{array}$ & $\begin{array}{l}a \\
b\end{array}$ & $\begin{array}{ll}0 & 0 \\
0 & 1 \\
1 & 0 \\
1 & 1 \\
\end{array}$ & $\begin{array}{l}1.42 \pm 0.04 \\
1.39 \pm 0.04 \\
1.79 \pm 0.08 \\
1.53 \pm 0.04\end{array}$ & $\begin{array}{l}a \\
a \\
c \\
b\end{array}$ & $\begin{array}{l}1.35 \pm 0.04 \\
1.46 \pm 0.04 \\
1.52 \pm 0.04 \\
1.80 \pm 0.09\end{array}$ & $\begin{array}{l}a \\
b \\
c \\
d\end{array}$ & ns & \\
\hline BL Flour & $\begin{array}{l}0 \\
1\end{array}$ & 0.35 & ns & & $\begin{array}{l}0.33 \pm 0.004 \\
0.37 \pm 0.003\end{array}$ & $\begin{array}{l}a \\
b\end{array}$ & $\begin{array}{c}0.347 \pm 0.002 \\
0.35 \pm 0.005\end{array}$ & $\begin{array}{l}a \\
b\end{array}$ & $\begin{array}{ll}0 & 0 \\
0 & 1 \\
1 & 0 \\
1 & 1\end{array}$ & ns & & ns & & $\begin{array}{l}0.32 \pm 0.003 \\
0.33 \pm 0.004 \\
0.37 \pm 0.003 \\
0.37 \pm 0.003\end{array}$ & $\begin{array}{l}a \\
b \\
c \\
c\end{array}$ \\
\hline TL Flour & $\begin{array}{l}0 \\
1\end{array}$ & 2.41 & $\begin{array}{l}2.28 \pm 0.03 \\
2.53 \pm 0.05\end{array}$ & $\begin{array}{l}a \\
b\end{array}$ & $\begin{array}{l}2.46 \pm 0.05 \\
2.36 \pm 0.03\end{array}$ & $\begin{array}{l}\mathrm{b} \\
\mathrm{a}\end{array}$ & $\begin{array}{l}2.31 \pm 0.03 \\
2.51 \pm 0.04\end{array}$ & $\begin{array}{l}a \\
b\end{array}$ & $\begin{array}{ll}0 & 0 \\
0 & 1 \\
10 \\
11\end{array}$ & $\begin{array}{c}2.27 \pm 0.03 \\
2.285 \pm 0.03 \\
2.64 \pm 0.06 \\
2.43 \pm 0.03\end{array}$ & $\begin{array}{l}a \\
a \\
c \\
b\end{array}$ & $\begin{array}{l}2.22 \pm 0.03 \\
2.34 \pm 0.03 \\
2.40 \pm 0.03 \\
2.68 \pm 0.05\end{array}$ & $\begin{array}{l}a \\
b \\
b \\
c\end{array}$ & ns & \\
\hline FL Dough & $\begin{array}{l}0 \\
1\end{array}$ & 1.14 & $\begin{array}{l}0.94 \pm 0.07 \\
1.33 \pm 0.11\end{array}$ & $\begin{array}{l}a \\
b\end{array}$ & $\begin{array}{l}1.24 \pm 0.11 \\
1.04 \pm 0.07\end{array}$ & $\begin{array}{l}\mathrm{b} \\
\mathrm{a}\end{array}$ & ns & & $\begin{array}{ll}0 & 0 \\
0 & 1 \\
1 & 0 \\
1 & 1\end{array}$ & $\begin{array}{l}1.11 \pm 0.07 \\
0.79 \pm 0.07 \\
1.37 \pm 0.14 \\
1.29 \pm 0.07\end{array}$ & $\begin{array}{l}b \\
a \\
c \\
c\end{array}$ & ns & & ns & \\
\hline BL Dough & $\begin{array}{l}0 \\
1\end{array}$ & 0.33 & $\begin{array}{l}0.35 \pm 0.01 \\
0.31 \pm 0.02\end{array}$ & $\begin{array}{l}\mathrm{b} \\
\mathrm{a}\end{array}$ & $\begin{array}{l}0.29 \pm 0.02 \\
0.37 \pm 0.02\end{array}$ & $\begin{array}{l}a \\
b\end{array}$ & ns & & $\begin{array}{ll}0 & 0 \\
0 & 1 \\
1 & 0 \\
1 & 1\end{array}$ & ns & & ns & & $\begin{array}{c}0.31 \pm 0.015 \\
0.28 \pm 0.02 \\
0.35 \pm 0.014 \\
0.38 \pm 0.014\end{array}$ & $\begin{array}{l}\mathrm{a} \\
\mathrm{a}\end{array}$ \\
\hline FL bread & $\begin{array}{l}0 \\
1\end{array}$ & 0.65 & ns & & $\begin{array}{c}0.81 \pm 0.16 \\
0.49 \pm 0.1\end{array}$ & $\begin{array}{l}\mathrm{b} \\
\mathrm{a}\end{array}$ & ns & & $\begin{array}{ll}0 & 0 \\
0 & 1 \\
1 & 0 \\
1 & 1\end{array}$ & ns & & ns & & $\begin{array}{c}0.64 \pm 0.11 \\
0.98 \pm 0.16 \\
0.49 \pm 0.1 \\
0.48 \pm 0.1\end{array}$ & $\begin{array}{l}a \\
b \\
a \\
a\end{array}$ \\
\hline PBL Bread & $\begin{array}{l}0 \\
1\end{array}$ & 0.84 & $\begin{array}{l}0.90 \pm 0.07 \\
0.78 \pm 0.11\end{array}$ & $\begin{array}{l}\mathrm{b} \\
\mathrm{a}\end{array}$ & $\mathrm{ns}$ & 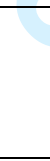 & $\begin{array}{l}0.97 \pm 0.07 \\
0.71 \pm 0.10\end{array}$ & $\begin{array}{l}\mathrm{b} \\
\mathrm{a}\end{array}$ & $\begin{array}{ll}0 & 0 \\
0 & 1 \\
1 & 0 \\
1 & 1 \\
\end{array}$ & $\begin{array}{l}0.86 \pm 0.07 \\
0.95 \pm 0.07 \\
0.87 \pm 0.14 \\
0.69 \pm 0.07\end{array}$ & $\begin{array}{c}b \\
c \\
a b c \\
a\end{array}$ & & & & \\
\hline SBL Bread & $\begin{array}{l}0 \\
1\end{array}$ & 0.97 & $\begin{array}{c}0.85 \pm 0.05 \\
1.1 \pm 0.08\end{array}$ & $\begin{array}{l}a \\
b\end{array}$ & $\begin{array}{c}0.9 \pm 0.08 \\
1.05 \pm 0.05\end{array}$ & $\begin{array}{l}a \\
b\end{array}$ & $\begin{array}{l}1.11 \pm 0.05 \\
0.85 \pm 0.04\end{array}$ & $\begin{array}{l}\mathrm{b} \\
\mathrm{a}\end{array}$ & $\begin{array}{ll}0 & 0 \\
0 & 1 \\
1 & 0 \\
1 & 1 \\
\end{array}$ & ns & & $\begin{array}{l}0.94 \pm 0.05 \\
0.76 \pm 0.05 \\
1.29 \pm 0.06 \\
0.92 \pm 0.08\end{array}$ & $\begin{array}{l}\mathrm{b} \\
\mathrm{a} \\
\mathrm{c} \\
\mathrm{b}\end{array}$ & $\begin{array}{c}1.2 \pm 0.06 \\
0.60 \pm 0.08 \\
1.02 \pm 0.05 \\
1.08 \pm 0.05 \\
\end{array}$ & $\begin{array}{l}c \\
a \\
b \\
b\end{array}$ \\
\hline TL Bread & $\begin{array}{l}0 \\
1\end{array}$ & 2.46 & $\begin{array}{l}2.34 \pm 0.02 \\
2.58 \pm 0.03\end{array}$ & $\begin{array}{l}a \\
b\end{array}$ & $\begin{array}{l}2.57 \pm 0.03 \\
2.35 \pm 0.02\end{array}$ & $\begin{array}{l}\mathrm{b} \\
\mathrm{a}\end{array}$ & $\begin{array}{l}2.64 \pm 0.02 \\
2.27 \pm 0.03\end{array}$ & $\begin{array}{l}\mathrm{b} \\
\mathrm{a}\end{array}$ & $\begin{array}{ll}0 & 0 \\
0 & 1 \\
1 & 0 \\
1 & 1\end{array}$ & $\begin{array}{l}2.38 \pm 0.02 \\
2.30 \pm 0.02 \\
2.76 \pm 0.04 \\
2.41 \pm 0.02\end{array}$ & $\begin{array}{l}\mathrm{b} \\
\mathrm{a} \\
\mathrm{c} \\
\mathrm{b}\end{array}$ & $\begin{array}{l}2.46 \pm 0.02 \\
2.22 \pm 0.02 \\
2.83 \pm 0.02 \\
2.33 \pm 0.03\end{array}$ & $\begin{array}{l}\text { c } \\
a \\
d \\
b\end{array}$ & $\begin{array}{l}2.84 \pm 0.02 \\
2.30 \pm 0.03 \\
2.45 \pm 0.02 \\
2.25 \pm 0.02\end{array}$ & $\mathrm{c}$ \\
\hline
\end{tabular}

${ }_{1}^{1}$ Mean values \pm standard deviation. Within each parameter, values with different letters differ significantly from each other.

2 Coded levels refer to $7.5 \%$ (0) ang 15\% (1) wheat flour replacement by non-wheat flours in sample formulation. 


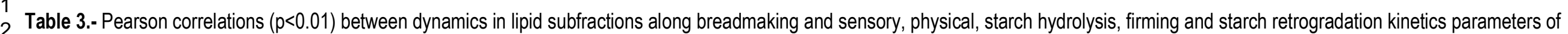

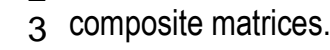

\begin{tabular}{|c|c|c|c|c|c|c|c|}
\hline & Parameters & $F L_{f b}$ & $P B L_{f b}$ & $S B L_{f b}$ & $F L_{\text {mixing }}$ & $B L_{\text {mixing }}$ & $S L_{\text {mixing }}$ \\
\hline \multirow{10}{*}{$\begin{array}{l}\text { Sensory } \\
\text { Evaluation }\end{array}$} & cell uniformity & & & -0.8999 & -0.5531 & & -0.3899 \\
\hline & cell size & & & -0.7689 & & & \\
\hline & brightness & & & 0.8101 & 0.6801 & -0.4999 & \\
\hline & moistness & & & -0.8056 & -0.7616 & 0.4819 & \\
\hline & elasticity & & & -0.7679 & -0.6164 & & -0.5134 \\
\hline & smoothness & & & -0.5955 & & 0.5310 & \\
\hline & mouthfeel & & & 0.8101 & 0.6801 & -0.4999 & \\
\hline & adhesiveness & & & -0.5130 & & 0.5966 & \\
\hline & cohesiveness & & & 0.7553 & 0.7868 & -0.3933 & \\
\hline & chewiness & & & 0.7627 & 0.8081 & & 0.4358 \\
\hline \multirow{6}{*}{$\begin{array}{c}\text { Physical } \\
\text { Characteristics }\end{array}$} & Specific volume & & 0.4533 & & 0.4738 & & 0.6346 \\
\hline & Hardness & & -0.6398 & & -0.6053 & 0.4569 & -0.3810 \\
\hline & Cohesiveness & 0.6931 & 0.6247 & & & -0.5931 & \\
\hline & Springiness & & & & & -0.3805 & \\
\hline & Crumb whiteness & 0.3994 & 0.5336 & & & -0.4174 & \\
\hline & Cell density & & & -0.6074 & -0.6577 & & -0.7097 \\
\hline \multirow{5}{*}{$\begin{array}{c}\text { Starch } \\
\text { Digestibility }\end{array}$} & $C_{\infty}$ & -0.4675 & 0.4634 & 0.7548 & & & \\
\hline & $k_{d}$ & & -0.5298 & & 0.4543 & & \\
\hline & RDS & & & & & -0.5742 & \\
\hline & SDS & & & & -0.5234 & & \\
\hline & RS & & & -0.5372 & -0.5298 & 0.5449 & \\
\hline \multirow{4}{*}{ Firming kinetics } & $T_{\infty}$ & & & 0.5912 & 0.5895 & -0.6217 & \\
\hline & $k_{f}$ & & & -0.8353 & -0.5777 & & -0.4263 \\
\hline & $n_{f}$ & -0.5041 & & & & 0.5461 & 0.4678 \\
\hline & $T_{0}$ & & -0.6686 & -0.3521 & -0.5707 & 0.4032 & -0.3945 \\
\hline Amylopectin & $\Delta H_{\infty}$ & & 0.6016 & 0.6365 & & & \\
\hline Retrogradation & $k_{r}$ & & 0.3928 & & & & \\
\hline kinetics & $n_{r}$ & & -0.6741 & -0.5608 & -0.3852 & 0.4230 & \\
\hline
\end{tabular}

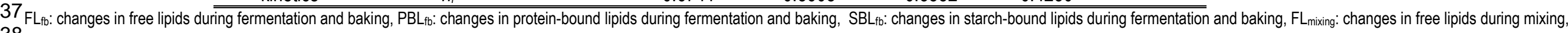

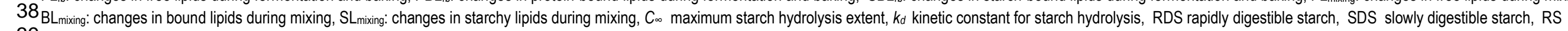

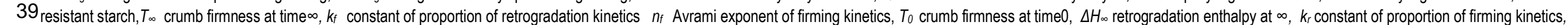
$40 n_{r}$ Avrami exponent of retrogradation kinetics. 


\section{$210 \times 297 \mathrm{~mm}(180 \times 180 \mathrm{DPI})$}

Figure 1.- Lipid distribution (\%) in flour (A), dough (B) and bread (C) samples. Blended samples were based on: wheat $(W)$, teff $(T)$, green pea (GP), and buckwheat (BW). Three digit bread sample code refers to low (0) ang high (1) wheat flour replacement by T: GP: BW flours in sample formulation. FL: free lipids, BL: bound lipids, SL: starchy lipids, PBL: protein-bound lipids, SBL: starch-bound lipids, TL: total lipids. 
